\title{
An Adoption Diffusion Model of RFID-Based Livestock Management System in Australia
}

\author{
Mohammad Alamgir Hossain and Mohammed Quaddus \\ Graduate School of Business, \\ Curtin University of Technology, \\ Perth, WA, Australia
}

\begin{abstract}
Many countries, like Australia, have introduced a radio frequency identification (RFID) based livestock identification and management system, which can be used for condition monitoring and fault prognosis during an outbreak situation. This paper examines the adoption process and its subsequent diffusion and extended usage of RFID in Australian livestock management practices, and proposes a research model. The model is primarily built on Rogers' innovation-diffusion theory and Oliver's expectation-confirmation theory, with some logical modifications. It posits that while adoption of RFID may be the result of legislative pressure, its further diffusion is an evaluative process, which is judged against "satisfaction" and "performance" derived from RFID systems. The implications of these and other related concepts are also discussed. Hypotheses are developed which can be tested via empirical study. The proposed model has both theoretical and practical implications. Although it is developed on the basis of the Australian livestock industry, it can be used in other countries and also in other applications with some industry-specific modifications.
\end{abstract}

Keywords: RFID, adoption, diffusion, extended use, livestock industry, Australia.

\section{Introduction}

Radio frequency identification (RFID) technology is one of the most effective enabling technologies in identifying an object uniquely and keeping the desired data as long as required, which can later be retrieved as information. Along with tens of other applications, RFID is a very efficient method of identifying animals and collecting data more quickly, and is potentially a revolutionary innovation for the food industry. For livestock markets, the data and information serve as the "certificate" of the product and the international livestock market is increasingly demanding an RFID-generated data and information system from the livestock and livestock products supplying countries that can be used for condition monitoring and fault prognosis in the event of an outbreak situation (Sullivan 2004). The pressure intensified with the scrutiny of various government agencies. To this end, some countries such as Canada, Australia, and Uruguay, as well as numerous European countries, passed legislation on mandatory use of auto- identification, while other 
countries such as the United States, Malaysia, and Japan are implementing the system on a volunteer basis (Patent et al. 2006). Australia has the world's first and largest RFID-enabled national livestock identification system, called NLIS (Tonsor and Schroeder 2006). When integrated with post-slaughter tracking systems, the NLIS database allows for rapid and accurate tracing of cattle in the event of a disease outbreak or residue incident and saves the industry from more losses than would otherwise be the case. For example, in July 2008, Russia, Australia's fourth largest beef export market, banned three kangaroo processing plants and a beef facility because of microbial contamination (ABC 2008). If NLIS could not track the sources of the contamination quickly, the entire Australian meat industry would have suffered from this ban.

The Australian meat and livestock industry is regarded as one of the largest in the world and is renowned for its "clean and green" beef. Australia is the second-largest exporter of beef, mutton, and lamb in the world, exporting to more than 100 countries (Tonsor and Schroeder 2006), and world's largest exporter of beef (ABARE 2008). During 2007-2008, the gross value of livestock production was $\$ 41.5$ billion, contributing 63 percent of the gross value of agricultural product ( $\$ 65.4$ billion). A significant portion of this products was exported, contributing 53 percent of the agribusiness's export in 2007-2008, $\$ 14.5$ billion of the total $\$ 27.5$ billion (ABARE 2008).

Most studies on RFID have dealt with technology issues (frequency standardization, tag orientation), security, privacy, and implementation issues primarily in supply chain and logistics management, although several studies have been undertaken in the RFID adoption diffusion area (Chang et al. 2008; Cheng and Yang 2007; Huyskens and Loebbecke 2007; Krasnova et al. 2008; Lee and Shim 2007; Matta and Moberg 2006, 2007; Ranganathan and Jha 2005; Schmitt et al. 2008; Schmitt et al. 2007; Sharma and Citurs 2005). The adoption of RFID in the Australian livestock industry is, however, a special type of adoption as the government imposed the legal requirement of using this technology for cattle identification. However, farmers may also use RFID voluntarily for identifying other animals or in other livestock applications. Therefore, it would seem to be interesting to examine how farmers embraced this technology and whether they got what they expected. It is likely that if they are satisfied they would diffuse this technology and possibly use it for other applications. Alternatively, if they are not satisfied, they are likely to use this technology only for mandated purposes. However, unfortunately, no significant work has been performed to explain the farmers' adoption and diffusion behavior in RFIDbased livestock identification and management field. This paper addresses and attempts to close this research gap. Equipped with a background of adoption and diffusion of innovation, this paper develops a research model to examine and identify the factors affecting the adoption-diffusion and extended use of RFID in the livestock industry. The two dominant research questions of this study are

1. What are the factors that influence the farmers' adoption decision of RFID technology in their livestock identification operation?

2. What are the factors influencing the diffusion and extended use decision of RFID in livestock management operations? 


\section{Background}

Adoption diffusion of an innovation has been studied primarily with three theories: innovation-diffusion theory (IDT), theory of reasoned action (TRA), and technology acceptance model (TAM). While IDT focuses on the diffusion processes of an innovation, the TRA and TAM models explain the relationship between actual use of a technology and user attitudes, perceptions, and beliefs (Xu and Quaddus 2007). RFID adoption is more or less imposed rather than voluntary, which is based on the attitude of the users or perceived usefulness, while RFID diffusion is believed to be more dependent on performance evaluation rather than belief or attitude. Bhattacherjee (2001) argues that not only adoption but continued use is necessary for an innovation's ultimate success and has used expectation confirmation theory (ECT) in explaining IS continuance, although ECT is primarily used in consumer behavior literature. This study, based on IDT and ECT, develops a theoretically grounded, comprehensive framework to investigate the antecedents of RFID adoption, diffusion, and extended use, which is further refined using theoretical and empirical findings from prior literature. The following subsections discuss the two underlying theories as they relate to adoption diffusion and continued use of an innovation.

\subsection{Innovation Diffusion Theory (IDT)}

An "innovation is the adoption of a change which is new to an organization and to the relevant environment" (Knight 1967, p. 467). Diffusion is "the process by which an innovation is communicated through certain channels over time among the members of a social system" (Rogers 1995, p. 5). Therefore, RFID can certainly be examined by IDT.

IDT proposes that potential adopters of an innovation must gain some knowledge about the innovation, then be persuaded of its value, decide to adopt and implement it, and confirm the decision to adopt the innovation. For pursuing the maximum benefits, however, mere adoption of RFID is not sufficient; rather, it is necessary to institutionalize this technology into routine operations and practices and extend its use to different applications, where possible, suitable, or profitable. The continued and extended use behavior is different from and possibly more important than its initial adoption because many RFID adopters are initially driven by mandatory pressure and later choose different level of use depending on their internal judgment. IDT is silent, not explaining how adopters go to the next stage of diffusion and to further innovative applications. Moreover, IDT is primarily based on individual-level adoption decisions (Eveland and Tornatzky 1990), but RFID adoption needs to be examined from government and organizational perspectives because it involves many national policies and requires modification of organizational structures and operations.

\subsection{Expectation-Confirmation Theory}

Expectation-confirmation theory (ECT) is widely used in the consumer behavior literature to study consumer satisfaction and post-purchase behavior. Post-purchase behavior is somewhat related to the continued and extended use characteristics of an innovation. The process by which consumers reach repurchase intentions in an ECT 
framework is as follows (Oliver 1980, p. 462): First, buyers form an initial expectation of a specific product or service prior to purchase. Second, consumption reveals a perceived quality level, which is influenced by expectations. Third, they determine the extent to which their expectation is confirmed. Fourth, they form a satisfaction based on their confirmation level and expectation. Finally, satisfied consumers form a repurchase intention, while dissatisfied consumers discontinue its subsequent use.

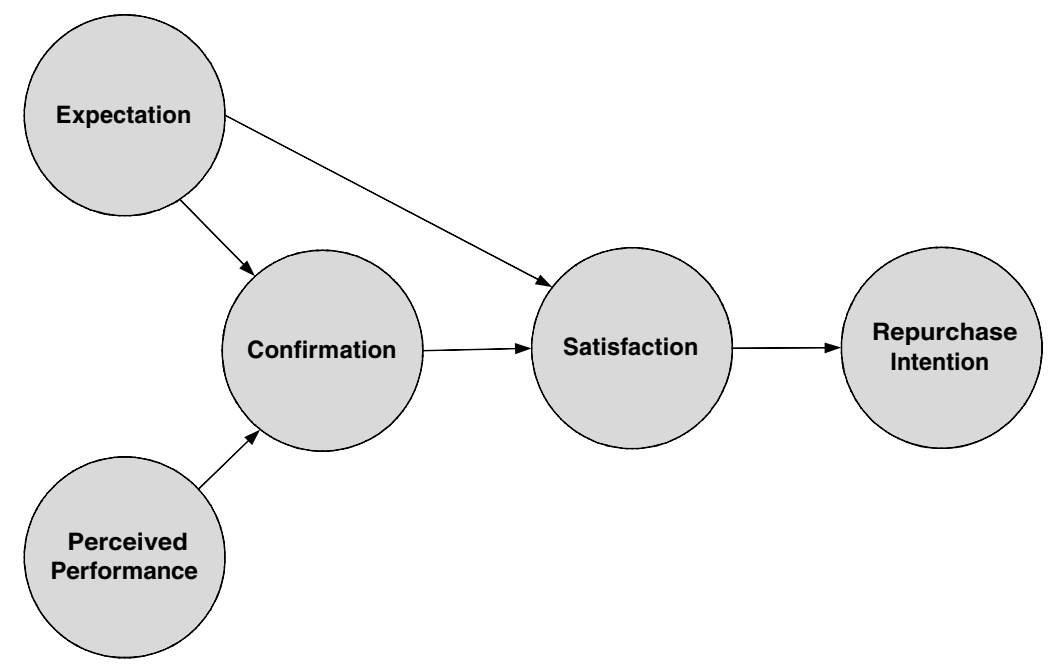

Fig. 1. Expectation-Confirmation Theory (Adapted from Figure 1 in A. Bhattacherjee, "Understanding Information Systems Continuance: An Expectation-Confirmation Model," MIS Quarterly (25:3), pp. 351-370. Copyright (C) 2001, Regents of the University of Minnesota. Used with permission.)

In ECT, expectation acts as the frame-of-reference to measure confirmation and satisfaction. ECT, however, does not explain the basis of expectations and ignores the driving forces behind adopting a product, service, or innovation. It ignores the mandatory introduction of a product or service; rather, it is based on voluntary decisions. In a mandatory system, the expectations are shaped and biased by the imposing authority and, therefore, not an independent variable as proposed in ECT.

\subsection{Conceptual Framework}

This study suggests that farmers, driven by the market and/or legislative requirements, gather and utilize all available information (from internal and external sources), share information, and develop and adjust their expectations in developing rational expectations (Au and Kauffman 2003) before they adopt RFID. Adoption drives RFID to further diffusion. Meanwhile, the expectations are modified. Eventually the satisfied farmers diffuse RFID into their routine operations while dissatisfied farmers may use it for limited operation(s). Farmers in Australia do not have the choice to reject RFID use as it is mandatory for cattle identification. Moreover, some satisfied 
farmers may voluntarily use RFID for extended use. Satisfaction, however, is measured against the level of confirmation of the expectations, and the performance of RFID. Thus the framework is presented in two parts: External factors $\rightarrow$ Knowledge $\rightarrow$ Adoption; and Expectations $\rightarrow$ Satisfaction $\rightarrow$ Diffusion and Extended Use. We use this conceptual framework for the development of the RFID adoptiondiffusion $^{+}$model, which is discussed in the following section.

\section{The Research Model and Hypotheses Development}

Figure 2 depicts the proposed model. The following section describes the constructs of the research model.

\subsection{RFID Knowledge}

RFID knowledge describes the amount of knowledge in the field of RFID that a farmer accumulates in theory and practice. In this study, the RFID knowledge construct consists of basic, technical, and technological RFID knowledge. Basic RFID knowledge refers to knowledge about the existence and potential benefits of RFID. Technical RFID knowledge is knowledge about the state-of-the-art of RFID technology. Technological RFID knowledge is about technological laws (scientific and IT mathematics), functional rules (RFID standard and frequency use), structural rules (depth of integration), and socio-technical understanding (such as ethics, privacy, etc.) of RFID. RFID knowledge itself is dependant of external information sources and the organization's internal information sources (Tellkamp et al. 2009).

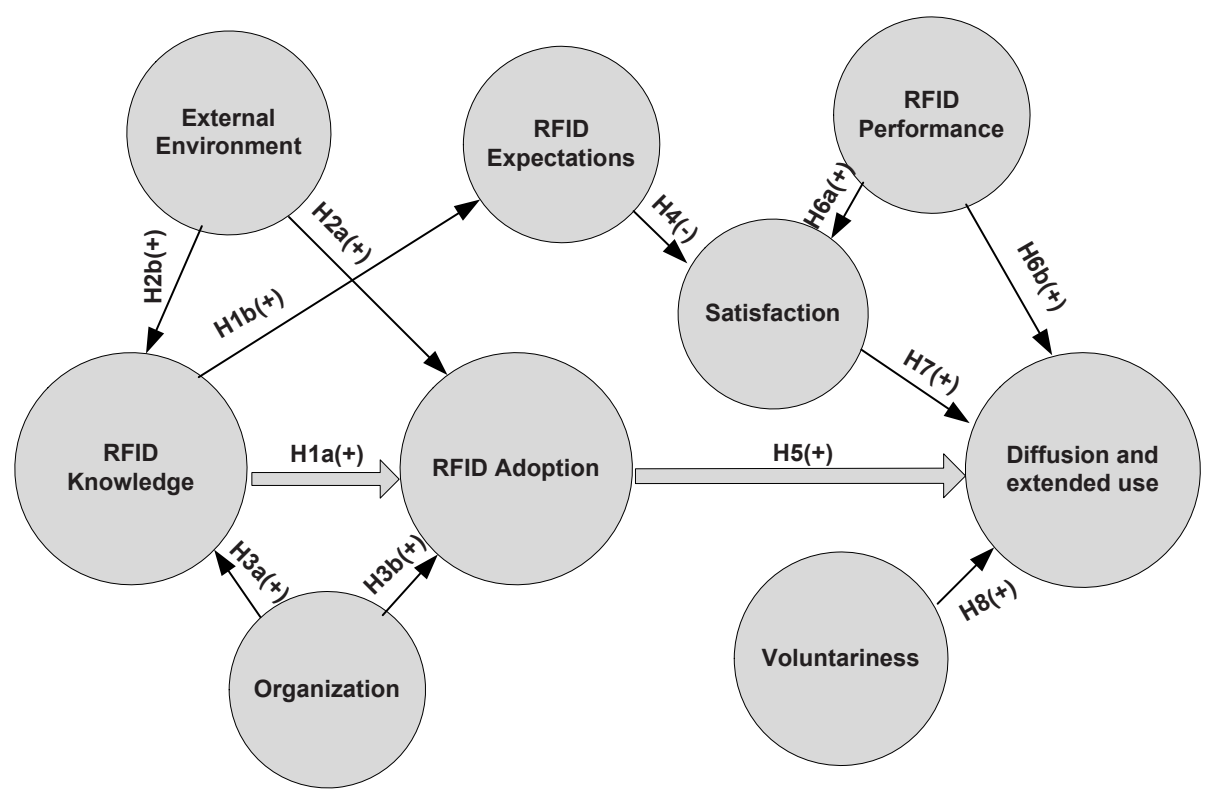

Fig. 2. The Proposed Research Model of RFID Adoption-Diffusion ${ }^{+}$ 
Furthermore, the amount of RFID knowledge influences the likelihood of RFID adoption(Lee and Shim 2007; Ranganathan and Jha 2005; Tellkamp et al. 2009) and generates more realistic and rational RFID expectations (Au and Kauffman 2003).

Hypothesis la: RFID knowledge positively influences the speed and extent of RFID adoption.

Hypothesis 1b: RFID knowledge positively influences RFID expectations in livestock farms.

\subsection{External Environment}

The external environment is the global control where the organization operates and it is beyond the organization's control but is important in decision-making behavior (Quaddus and Hofmeyer 2007). External environment has been recognized as playing a very significant role in adoption-diffusion research, including RFID adoption (Sharma and Citurs 2005). Related to RFID adoption, the external environment consists of external pressure (Matta and Moberg 2007), government (Matta and Moberg 2007; Zhu et al. 2003), external information sources (Jeyaraj et al. 2006 ; Matta and Moberg 2007), and industry-wide standardization and cost (Brown and Russell 2007; Cheng and Yang 2007; Juban and Wyld 2004).

External pressure: External pressure consists of government pressure (Kuan and Chau 2001) and market pressure (Chang et al. 2008; Ranganathan and Jha 2005). A practical reason for livestock farmers to adopt RFID is government policy and regulations. Like Australia, a growing number of animal exporting countries have introduced legislation on compulsory RFID-based livestock management systems. Therefore, farmers do not have any choice but to adopt RFID technology. Another reason for livestock farmers to adopt RFID is because of the increasing market pressure for RFID-based animal tracking systems (Li and Visich 2006).

Government: Government can play an important role in RFID adoption and diffusion through information provision, research and development policies and facilities, incentives for the adopters, and building and enhancing the infrastructure (Scupola 2003).

External information sources: Farmers acquire RFID information from external information sources, including farm magazines, government agencies (Kettinger 1994), and through interpersonal channels such as other adopters who are similar in socioeconomic status (Ghadim and Pannell 1999). External information sources contribute to livestock farmers acquiring RFID knowledge and also motivates the farmers to adopt RFID.

Industry-wide standardization and cost: One of the main inhibitors of RFID adoption is the lack of standardization and the cost of RFID tags (Schmitt et al. 2008). Although the RFID standards (ISO11784/11785) are defined by the International Standards Organization (ISO) to use LF $134.2 \mathrm{KHz}$, farmers are easily confused when they find too many providers with many different types of tags and readers. They are afraid of buying tags and readers from different providers because they think that the tags might not be read by readers from a different company (readability). That brings 
the fear of not being able to read the tags in different countries and hinders the process of a global system of livestock identification (interoperability). Therefore, adopters are looking for an industry-wide standard system (Brown and Russell 2007; Cheng and Yang 2007; Juban and Wyld 2004; Sharma and Citurs 2005) and the tags need be cheaper (Schmitt et al. 2008; Sharma and Citurs 2005; Sharma et al. 2007). As a whole,

\section{Hypothesis 2a: External environment positively influences RFID adoption.} Hypothesis 2b: External environment positively influences RFID knowledge.

\subsection{Organizational Factors}

Tornatzky and Fleischer (1990) argued that organizational factors must be considered in any organizational innovation adoption research. Organizational variables such as (top) management attitude towards adoption of RFID with adequate funding and expertise ensures RFID adoption (Brown and Russell 2007; Huyskens and Loebbecke 2007; Krasnova and Weser 2008; Ranganathan and Jha 2005; Schmitt et al. 2007; Sharma and Citurs 2005; Sharma et al. 2007). Organizational size also is an important factor as the RFID integration-depth comes with the physical, financial, and technological resources of the farm (Brown and Russell 2007; Huyskens and Loebbecke 2007; Matta and Moberg 2006, 2007). Organizational size facilitates knowledge acquisition (and/or knowledge generation). Infrastructure-related facilities (IS/IT/ICT) available in the organization influence RFID adoption (Ranganathan and Jha 2005; Sharma and Citurs 2005; Sharma et al. 2007). As a whole,

\section{Hypothesis 3a: Organizational factors positively influence RFID knowl- edge for its adoption and diffusion among livestock farmers.}

Hypothesis 3b: Organizational factors positively influence RFID adoption in livestock farms.

\subsection{RFID Expectations}

RFID expectations are the expected attributes of RFID that are derived during the knowledge gathering phase, and are similar to the perceived characteristics of an innovation in IDT. This study differentiates expectation from attributes as some expectations are developed during the knowledge gathering phase, while some expectations are formed, or past expectations are modified, after the initial adoption, which means expectation is a continuous process rather than an initial and complete stage. Among the main attributes of an innovation in IDT (e.g., trialability, observability, relative advantage, complexity, and compatibility), empirical research and theoretical analysis found that relative advantage (Brown and Russell 2007; Krasnova et al. 2008), complexity (Chang et al. 2008; Schmitt et al. 2007), and compatibility (Schmitt et al. 2007) are consistently used attributes. Some other attributes, including profitability (Lindner 1987), cost (Sharma and Citurs 2005), market penetration, and risk and uncertainty (Ghadim et al. 2005) are also important for RFID study. However, adopters' expectations have a direct negative influence on 
satisfaction(Bearden and Teel 1983; Churchill and Surprenant 1982; Oliver 1980; Westbrook and Oliver 1981) as satisfaction is the difference between performance and expectations.

Hypothesis 4: RFID expectations negatively influence the level of satisfaction.

\subsection{RFID Adoption}

Mandatory RFID adoption drives farmers to identify their cattle with RFID tags. Successful RFID adoption motivates farmers to further diffuse the technology.

Hypothesis 5: RFID adoption positively influences RFID diffusion and extended use in livestock industry.

\subsection{Performance}

Performance is the manner of functioning or operating. Once the system is implemented, the performance of the RFID system is measured, including general (works as designed), financial (on-budget, return-on-investment, etc.), and technical (complexity, maintenance, data recovery) performance of the system. Churchill and Surprenant (1982) and Oliver and DeSarbo (1988) showed that performance has a direct and significant effect on satisfaction. However, Bhattacherjee (2001) and Schmitt et al. (2007) found that performance influences RFID diffusion.

Hypothesis 5a: RFID performance positively influences satisfaction of RFID use.

Hypothesis 5b: RFID performance positively influences diffusion and extended use of RFID system.

\subsection{Satisfaction}

Satisfaction is defined as "the summary of psychological state resulting when the emotion surrounding disconfirmation expectations is coupled with the consumer's prior feelings about the consumption experience" (Oliver 1981, p. 27). It is an evaluative response concerning the perceived outcomes of experience from that product or service. The satisfaction construct is composed of the presence of affect and the notion of satisfaction. Presence of affect is central to satisfaction, which is the evaluation of outcomes such as happy or regretful and so on. The notion of satisfaction is the degree of affect that the adopter is more or less inclined to continue use of the product. ECT holds that satisfaction has a direct effect on consumers' intention to repurchase a product or continue use (Anderson and Sullivan 1993; Oliver 1980).

Hypothesis 6: Satisfaction positively influences diffusion and extended use of the RFID system. 


\subsection{RFID Diffusion and Extended Use}

Diffusion and extended use is the only dependent variable of this study. This variable refers to the degree of use of the RFID systems in livestock management. Here, farmers do not have the luxury to decide not to continue RFID use as its use is mandatory in Australia (for cattle identification). However, farmers can decide the degree or depth of its use. Voluntarily, farmers may identify other animals and/or apply RFID for livestock operations including herd management and dairy management.

\subsection{Farmers' Voluntariness}

Farmers' RFID voluntariness is the degree to which farmers decide to implement RFID in livestock management operations of their own free will. It is the willingness to take initiative to try out RFID in livestock applications other than identification. Voluntariness is considered as one of the perceived characteristics for the diffusion of an innovation (Agarwal and Prasad 1997). Voluntariness may be varied with required investment and slack resources. However, this study postulates that farmers with more voluntariness would show interest and implement RFID in extended livestockmanagement application(s) than other farmers who are not volunteers.

\section{Hypothesis 7: Farmers' voluntariness positively influences RFID diffusion and extended use in livestock management processes.}

\subsection{Measurement Scale}

The variables of this study will be measured by adapting measurement scales from previous studies: organizational factors will be adapted from Patterson et al.'s (2003) organizational characteristics scale; satisfaction measure will be adapted from Westbrook and Oliver's (1981) satisfaction scale; competition measure will be adapted from Kuan and Chau (2001). The measure for attributes of RFID expectations will be adapted from the innovation-diffusion literature. Adapted measurement scales will be subjected to rigorous reliability and validity tests.

\section{Future Directions and Conclusion}

This article presents a research model for investigating the factors influencing the adoption, diffusion, and extended use of RFID technology - a subject that has not been well explored in the literature. Future research could test the entire research model. Parts of the model could also be extracted and investigated in detail. As the model is divided into two parts, future study could be conducted using different types of adopters. The model, including both of its main constructs and subfactors, can be taken as-is or fine-tuned for a comprehensive survey. Organizations embarking on RFID use can use the constructs and factors of the study to perform an internal audit to find out how they vary. The proposed model also provides guidelines for RFID adoption-diffusion practitioners and consultants. Therefore, this study will make two 
main contributions. First, it will test the theories in a new setting. Second, it will give practitioners new insights at the operational level as well assist with strategic decisions about effective diffusion policies and further RFID investments in the Australian livestock industry.

\section{References}

ABARE. Australian Commodities, December Quarter, ABARE Project 1163, Commonwealth of Australian, pp. 631-776 (2008), http : / / www . abareconomics . com/ interactive/08ac_Dec/htm/beef.htm (accessed November 12, 2009)

ABC. Australia's Livestock Industry Meets Over Russia Ban, Radio Australia News (2008), http://www.radioaustralia.net.au/news/stories/200807/ s2313053.htm (accessed November 16, 2009)

Agarwal, R., Prasad, J.: The Role of Innovation Characteristics and Perceived Voluntariness in the Acceptance of Information Technologies. Decision Sciences 28(3), 557-582 (1997)

Anderson, E.W., Sullivan, M.W.: The Antecedents and Consequences of Customer Satisfaction for Firms. Marketing Science 12(2), 125-143 (1993)

Au, Y.A., Kauffman, R.J.: What Do You Know? Rational Expectations in Information Technology Adoption and Investment. Journal of Management Information Systems 20(2), 49-76 (2003)

Bearden, W.O., Teel, J.E.: Selected Determinants of Consumer Satisfaction and Complaint Reports. Journal of Marketing Research (20), 21-28 (1983)

Bhattacherjee, A.: Understanding Information systems Continuance: An ExpectationConfirmation Model. MIS Quarterly 25(3), 351-370 (2001)

Brown, I., Russell, J.: Radio Frequency Identification Technology: An Exploratory Study on Adoption in the South African Retail Sector. International Journal of Information Management 27(4), 250-265 (2007)

Chang, S.-I., Hung, S.-Y., Yen, D.C., Chen, Y.-J.: The Determinants of RFID Adoption in the Logistics Industry: A Supply Chain Management Perspective. Communications of the Association for Information Systems 23(12), 197-218 (2008)

Cheng, Y.-H., Yang, A.S.: Investigating Key Factors of Deciding RFID's Adoption in Logistics Service Providers. Paper presented at the 11th International Conference on Computer Supported Cooperative Work in Design, Melbourne, Australia, April 26-28 (2007)

Churchill, J.G.A., Surprenant, C.: An Investigation into the Determinants of Customer Satisfaction. Journal of Marketing Research 19(4), 491-504 (1982)

Eveland, J.D., Tornatzky, L.G.: The Deployment of Technology. In: Tornatzky, L., Fleischer, M. (eds.) The Processes of Technological Innovation, pp. 117-147. Lexington Books, Lexington (1990)

Ghadim, A.K.A., Pannell, D.J.: A Conceptual Framework of Adoption of an Agricultural Innovation. Agricultural Economics (21), 145-154 (1999)

Ghadim, A.K.A., Pannell, D.J., Burton, M.P.: Risk, Uncertainty, and Learning in Adoption of a Crop Innovation. Agricultural Economics (33), 1-9 (2005)

Huyskens, C., Loebbecke, C.: RFID Adoption: Theoretical Concepts and Their Practical Application in Fashion. In: McMaster, T., Wastell, D., Ferneley, E., DeGross, J.I. (eds.) Organizational Dynamics of Technology-Based Innovation: Diversifying the Research Agenda, pp. 345-361. Springer, Boston (2007)

Jeyaraj, A., Rottman, J., Lacity, M.C.: A Review of the Predictors, Linkages, and Biases in IT Innovation Adoption Research. Journal of Information Technology 21(1), 1-23 (2006) 
Juban, R.L., Wyld, D.C.: Would You Like Chips With That? Consumer Perspectives of RFID. Management Research News 27(11/12), 29-44 (2004)

Kettinger, W.: National Infrastructure Diffusion and the US Information Super Highway. Information and Management 27(6), 357-368 (1994)

Knight, K.E.: A Descriptive Model of the Intra-Firm Innovation Process. The Journal of Business 40(4), 478-496 (1967)

Krasnova, H., Weser, L., Ivantysynova, L.: Drivers of RFID Adoption in the Automotive Industry. In: Proceedings of the 14th Americas Conference on Information Systems, Toronto, Canada, August 14-17 (2008)

Kuan, K., Chau, P.: A Perception-Based Model of EDI Adoption in Small Businesses Using a Technology-Organizational-Environmental Framework. Information and Management 38(3), 507-521 (2001)

Lee, C.-P., Shim, J.P.: An Exploratory Study of Radio Frequency Identification (RFID) Adoption in the Healthcare Industry. European Journal of Information Systems (17), 712 724 (2007)

Li, S., Visich, J.K.: Radio Frequency Identification: Supply Chain Impact and Implementation Challenges. International Journal of Integrated Supply Management 2(4), 407-424 (2006)

Lindner, R.K.: Adoption and Diffusion of Technology: An Overview. Technological Change in Postharvest Handling and Transportation of Grains in the Humid Tropics, Canberra, Australian Centre for International Agricultural Research (1987)

Matta, V., Moberg, C.: The Development of a Research Agenda for RFID Adoption and Effectiveness in Supply Chains. Issues in Information Systems 7(2), 246-251 (2006)

Matta, V., Moberg, C.: Defining the Antecedents for Adoption of RFID in the Supply Chain. Issues in Information Systems 8(2), 449-453 (2007)

Oliver, R.L.: A Cognitive Model for the Antecedents and Consequences of Satisfaction Decisions. Journal of Marketing Research 17, 460-469 (1980)

Oliver, R.L.: Measurement and Evaluation of Satisfaction Process in Retail Settings. Journal of Retailing 57, 25-48 (1981)

Oliver, R.L., DeSarbo, W.S.: Response Determinants in Satisfaction Judgements. Journal of Consumer Research 14(4), 495-507 (1988)

Patent, K., Roe, B., Fluharty, F.: Awareness and Intended Compliance of Beef Cattle Exhibitors in the National Animal Identification System. Journal of Extension 44(5) (2006),

http: //www.joe.org/joe/2006october/rb7.php

Patterson, K.A., Grimm, C.M., Corsi, T.M.: Adopting New Technologies for Supply Chain Management. Transportation Research Part E: Logistics and Transportation Review 37(2), 95-121 (2003)

Quaddus, M., Hofmeyer, G.: An Investigation into the Factors Influencing the Adoption of B2B Trading Exchanges in Small Business. European Journal of Information Systems 16, 202-215 (2007)

Ranganathan, C., Jha, S.: Adoption of RFID Technology: An Exploratory Examination from Supplier's Perspective. In: Proceedings of the 11th Americas Conference on Information Systems, Omaha, Nebraska, August 11-14 (2005)

Rogers, E.M.: Diffusion of Innovation. Free Press, New York (1995)

Schmitt, P., Michaelles, F., Fleisch, E.: Why RFID Adoption and Diffusion Takes Time: The Role of Standards in the Automotive Industry. AUTO-ID Labs (2008), http: //www.autoidlabs.org/single-view/dir/article/ 6/307/page.html (accessed November 11, 2009) 
Schmitt, P., Thiesse, F., Fleisch, E.: Adoption and Diffusion of RFID Technology in the Automotive Industry. In: Proceedings of the 15th European Conference on Information Systems, St. Gallen, Switzerland (2007)

Scupola, A.: The Adoption of Internet Commerce by SMEs in the South of Italy: An Environmental, Technological and Organizational Perspective. Journal of Global Information Technology Management 6(1), 51-71 (2003)

Sharma, A., Citurs, A.: Radio Frequency Identification (RFID) Adoption Drivers: A Radical Innovation Adoption Process. In: Proceedings of the 11th Americas Conference on Information Systems, Omaha, Nebraska, August 11-14 (2005)

Sharma, A., Citurs, A., Konsynski, B.: Strategic and Institutional Perspectives in the Adoption and Early Integration of Radio Frequency Identification (RFID). In: Proceedings of the 40th Hawaii International Conference on System Sciences, Big Island, Hawaii, January 3-6. IEEE Computer Society, Los Alamitos (2007)

Sullivan, L.: RFID Technology Could Be Used to Build a National Livestock-Tracking System. Information Week, January 12 (2004), http://www.informationweek.com/ news/management/showArticle.jhtml ?articleID $=17300330$ (accessed November 11, 2009)

Tellkamp, C., Wiechert, T., Thiesse, F., Fleisch, E.: The Adoption of RFID-Based Self-CheckOut-Systems at the Point-of-Sale: An Empirical Investigation. In: Proceedings of the 6th International Federation for Information Processing Conference on e-Commerce, e-Business, and e-Government, Turku, Finland, pp. 153-165. Springer, Boston (2009)

Tonsor, G.T., Schroeder, T.C.: Livestock Identification: Lessons for the U.S. Beef Industry from the Australian System. Journal of International Food and Agribusiness Marketing 18(4), 103-118 (2006)

Tornatzky, L.G., Fleischer, M.: Process of Technological Innovation. Lexington Books, Lexington (1990)

Westbrook, R.A., Oliver, R.L.: Developing Better Measures of Consumer Satisfaction: Some Preliminary Results. Advances in Consumer Research 8(1), 94-99 (1981)

Xu, J., Quaddus, M.: Exploring the Factors Influencing End Users' Acceptance of Knowledge Management Systems: Development of a Research Model of Adoption and Continued Use. Journal of Organizational and End User Computing 19(4), 57-79 (2007)

Zhu, K., Kraemer, K., Xu, S.: Electronic Business Adoption by European Firms: A CrossCountry Assessment of the Facilitators and Inhibitors. European Journal of Information Systems 12(4), 251-268 (2003)

\section{About the Authors}

Mohammad Hossain received a Bachelor of Science in Metallurgical Engineering from Bangladesh University of Engineering and Technology (BUET), a Master's in Advanced Engineering Management from BUET, and a Master's in e-Business from Edith Cowan University, Perth, Western Australia. He is currently working on his Ph.D. at Curtin University of Technology, Perth, Western Australia. Mohammad has varied work experience in engineering and IT administration and management in Australia and Bangladesh. His research interests are generally in the diffusion of IS/ICT, mathematical modeling, decision support systems, and electronic business and electronic commerce. Mohammad can be contacted at mohammad.hossain@postgrad.curtin.edu.au. 
Mohammed Quaddus received his Ph.D. from the University of Pittsburgh, and an MS from the University of Pittsburgh and the Asian Institute of Technology. His research interests are in information and knowledge management, decision support systems, group decision and negotiation support systems, multiple criteria decision making, business research methods, and the theories and applications of innovation diffusion process. Mohammed has published in a number of journals and contributed to several books and monographs. In 1996 and 2005, he received the "Researcher of the Year" award from the Curtin Business School, Curtin University of Technology, Australia. Currently he is a professor in the Department of Information and Decision Systems with the Graduate School of Business, Curtin University of Technology, Australia. Prior to joining Curtin, he was with the University of Technology-Sydney and with National University of Singapore. He also spent a year at the Information Management Research Centre, Nanyang Technological University, Singapore, and six months with the Asian Institute of Technology, Bangkok, Thailand. Mohammed can be contacted at mohammed.quaddus@gsb.curtin.edu.au. 